\title{
Optimization of unsteady operating modes of gas mains
}

\author{
Prytula N. ${ }^{1}$, Pyanylo Ya. ${ }^{2}$, Prytula M. ${ }^{1}$ \\ ${ }^{1}$ Institute of Gas Transmission PJSC Ukrtransgas \\ 16 Marshala Koneva str., 61004, Kharkiv, Ukraine \\ ${ }^{2}$ Centre of Mathematical Modelling of Pidstryhach Institute \\ for Applied Problems of Mechanics and Mathematics NAS of Ukraine \\ 15 Dudayev str., 79005, Lviv, Ukraine
}

(Received 15 December 2016)

\begin{abstract}
We consider the problem of operating mode control of compressor stations to ensure optimal operating mode of the main gas in a wide range of gas transmission volumes for the different options of initial and boundary conditions. We propose an adaptive algorithm of designing control actions, which ensures optimality criterion and does not violate existing technological limitations.
\end{abstract}

Keywords: gas main, optimal operating mode, optimality criterion, compressor station, control.

2000 MSC: $76 \mathrm{~N} 25,49 \mathrm{~J} 20$

UDC: 621.64 .029

\section{Introduction}

Under the term "gas main" (GM) we mean pipelines with existing compressor stations (CS) on them. Significant perturbation of gas flow parameters affects MG operation that occurs when changing the volume of consumption and transmission. All that cause unsteady operating modes that are described by nonlinear differential equations with partial derivatives, which in turn causes control parameter of gas-dynamic processes distributed on time and spatial coordinates. Therefore, the problem of control in terms of unsteady operating mode is rather complicated. The components of control vector are functions of power control of compressor station (CS) facilities and connection schemes of gas compressor units (GCU). Thus, the main gas pipeline is the object of control with distributed interdependent parameters and incomplete information. Incomplete information is caused by the impact on the process of gas transmission external factors like air temperature fluctuations, fluctuations of gas consumptions from the pipeline sections and uncontrolled leakage of gas due to leaks in facilities. One of the main problems of operational optimal control of gas transmission through pipelines is changing steady operating modes with an appropriate initial and boundary conditions. Another problem is supporting the system operating mode with existing technological limitations.

\section{Simulation of unsteady gas flows in pipeline}

The model of gas flow in a GM is based on models of gas flow in a pipeline and models of CS. Typically, the compressor stations on a gas main are of the same type. We assume that at the start point gas flow is steady. An unsteady flow of gas in the pipeline system is described in the form related differential equations with partial derivatives [1-4], which is based on the relevant laws of conservation. However, since the rate of change of gas temperature is much lower than the rate of change of gas pressure and gas flow when modelling gas-dynamic processes at intervals that are smaller than several days we can neglect dependence of temperature on time. This considerable simplify the solution of the boundary problem. The main characteristics of the gas flow in the unsteady mode are pressure $p(x, t)$ and volumetric flow $q(x, t)$. 
The compressor station (CS) model is based on structural technological piping diagrams and facility models [5]. The CS structure is represented as a graph in which facilities that have length are represented as edges, and the rest as vertices. The main facility, the gas compressor unit (GCU) consists of an engine and a centrifugal compressor (CC). It is known [5] that the CC inlet and outlet gas parameters are connected by a set of empirical dependences for reduced parameters that make it possible to take into consideration: the deviation of CS inlet gas parameters $\left(z_{i n}, R, T_{i n}\right)$ from their reduced values $\left(z_{p r}, R_{p r}, T_{p r}\right)$ and the deviation of the actual CC rotational speed $n$ from its nominal value $n_{n}$.

We can find the polytropic coefficient from the dependence $T_{\text {out }} z_{o u t}=T_{i n} z_{i n} \varepsilon^{\frac{k-1}{k \cdot \eta_{p o l}}}$ and use it in the formula

$$
\varepsilon^{\frac{k-1}{k \eta_{p o l}}}=\left(\frac{n}{n_{n}}\right)^{2} \frac{z_{p r} T_{p r} R_{p r}}{z_{i n} T_{i n} R}\left(\varepsilon_{n}^{\frac{k-1}{k \eta_{p o l}}}-1\right)+1 .
$$

The CC internal capacity is calculated using the following formula:

$$
N_{i}=\left(\frac{n}{n_{n}}\right)^{3} \rho \frac{m z_{p r} T_{p r} R_{p r} q_{p r}}{(m-1) \eta_{p o l} 60}\left(\varepsilon^{\frac{m-1}{m}}-1\right)
$$

in which $m$ is CC polytropic coefficient, $\eta_{p o l}$ is CC polytropic efficiency, $n$ is CC rotational speed, $q$ is CC fuel costs, $N_{i}$ is CC internal capacity; $z_{p r}, R_{p r}, T_{p r}$ is gas parameters for which CC characteristics are experimentally determined; $n_{n}$ is CC rotational speed.

There is a set of technological constrains on the following:

- maximum volumetric flow rate of a CC;

- CC rotational shaft speed $\left(n_{\min } \leqslant n \leqslant n_{\max }\right)$;

- maximum capacity of a GCU engine;

- CC maximum outlet pressure, which is determined by the pipe strength on the CC outlet;

- maximum temperature on the outlet of a $\mathrm{CC}$, defined by the insulating coating of pipelines;

- minimum value of the output pressure of each CC;

- conditions associated with a given level of stability of the CC (distance from the surge zone).

\section{Optimal operating modes of a gas main}

3.1. Optimal scheduling of operating modes [6-8]. We consider a gas main (GM), which consists of sections of pipelines, lumped consumptions and extractions, gas compressor stations and GCU with the same type of gas turbine engines. Input data for calculation of operating modes of GM can be given in several ways. Basically pressure on the outlet of the system, gas flow on the inlet and the gas flow of the consumptions or extractions on the sections are considered as given data. Such input data are considered typical. Many steady operating modes satisfy input data. The input data for calculation of operating modes of GM can be specified in several ways. These modes may differ in the number of operating CS's, the number of operating GCUs in each CS, GCU performance parameters, volumes of gas accumulated within the system and its distribution along sections of the pipelines, fuel gas costs, and (if gas is cooling) operating modes of air cooling units (ACU) (the number of ACU's and fans used).

The steady operation of one pipeline is uniquely defined by given pressure and gas flow on the inlet or outlet or is uniquely defined by gas pressure on the inlet and outlet of a pipeline [9]. The CS operating mode can be defined by inlet or outlet pressure, the speed of centrifugal compressors and the number of them and CS capacity. It is obvious that the optimal mode is specified clearly. Obviously, the optimal operating mode requires a certain amount of accumulated gas. Each volume of accumulated gas require a relevant operating mode and therefore different fuel gas costs. 
3.2. Optimal control of gas-dynamic processes in a GM. The numerical experiments showed that the most suitable control parameter is CS capacity. There are many solutions in the control problems, and thus numerous control methods [10-14]. Therefore, there is a problem of optimal choice of control parameters that satisfy the numerical characteristics, which is the quality criterion. Thus, the optimal control problem is to find a control $\bar{u}(t)$ that implements the goal for which the functional (the quality criterion) takes the extreme value. The corresponding phase trajectory $\bar{x}(t)$ is called the optimal trajectory and process $(\bar{x}(t), \bar{u}(t))$ is called the optimal process. In this case, the complexity of finding optimal trajectories is that not every points on the optimal trajectory is the optimal operating mode.

For controlled processes the integral quality criterion is most frequently used. This means that the extreme functional provides the following criteria: a) optimal performance; b) the accuracy of the system (average deviation in phase coordinates); c) energy (energy costs); d) mixed integrated criteria.

\section{Problems and numerical experiments}

In the stage of development of system of finding control parameters of gas flow there are several problems - forecasting, optimal scheduling and optimal control. There are several control methods. Among them it is distinguished passive and active control. The passive control is performed with valves on a linear pipeline. The active control is performed with capacity change of GCU and CS in general, changes in a volume cross-flow between different gas pipelines, regulating the speed of flow out and flow in the system and so on. We can also include as active control facilities the following: delivery measuring station (DMS), reduction units, various types valves (control valve, shut down valve, throttle valve, check valve).

The first step in solving the problem of the finding control parameters of gas-dynamic processes in the GTS is the forecast. The forecasted operating mode should provide gas balance in the system with the required accuracy (the balance of inflow, consumption, extraction and transit). The second step is the optimal scheduling. The accuracy and optimality of scheduling directly affected by the accuracy of forecasting, which is specified during the day. The third step is the finding the initial and boundary conditions, analysis and finding control parameters. We specify and change control parameters under the specified optimal control criteria.

It is distinguished the problems of short-term and long-term optimal scheduling. For long-term scheduling, we use standard input data. Short-term scheduling requires additional input data. These data may be parameters of a certain steady operating mode, in particular the volume of accumulated gas in the distribution system and in the sections of gas mains.

The problem of choosing the CS operating mode on the gas main is to minimize the fuel cost and energy consumption of CS's. The problem is described as follows: for a given input $Q, P_{0}, P_{N+1}, q_{i}^{+}, q_{j}^{-}$ (flows, inlet and outlet pressures and pressure on the adjacent consumptions and extractions) find the following $\left(P_{a i}, P_{b i}, u_{i}\right) i=1, \ldots, N$ (inlet and outlet pressures and control parameters for $i$ th CS) that satisfy the condition

$$
F\left(P_{a 1}, P_{b 1}, \ldots, P_{a N}, P_{b N}\right)=N i\left(P_{a 1}, P_{b 1}, u_{1}\right)+\ldots+N i\left(P_{a N}, P_{b N}, u_{N}\right) \rightarrow \min .
$$

Minimizing the expression (1) it is possible that for some $i$ the condition $P_{a i}=P_{b i}$ is satisfied. We enumerate the pressure on the inlets and outlets of the CS and control parameters in the domain of technological constraints.

\section{Numerical experiments}

5.1. Problem of operating mode scheduling. Provided that all CS on the gas main have GCUs with similar characteristics and adjacent gas consumptions and extractions are small, it is necessary to enforce both conditions (principle of optimality): load first CS's along the gas main to the maximum possible pressure on the outlet and use the least number of CS. 


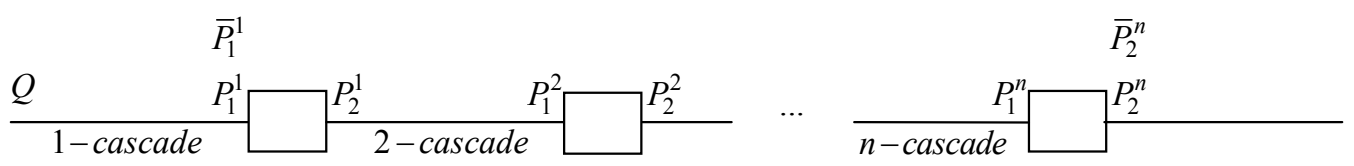

Fig. 1. Diagram of the gas man.

Under condition of underloaded CS's on the gas main only condition the minimum number of operating CS's does not always lead to optimal operating mode. We consider a single-strand pipeline with three CS's and adjacent pipeline sections, which are numbered from 1 to 3 in the direction of gas flow (Fig. 1). The diameter of pipelines is (internal) 1000 and $1400 \mathrm{~mm}$. The gas pressure on the inlet and outlet of the systems in the experiments remained constant. The volumetric flow rate for gas pipelines of various diameters were different. The results of numerical experiments are given in Table 1.

Table 1. Optimization of single-strand pipeline. Capacity of the pipeline: 69.12 million $\mathrm{m}^{3} /$ day for tubes $D=1400 \mathrm{~mm}$ and 34.56 million $\mathrm{m}^{3} /$ day for tubes $D=1200 \mathrm{~mm}$.

\begin{tabular}{|c|c|c|c|}
\hline \multirow{2}{*}{$\begin{array}{c}\text { Number of } \\
\text { operating mode }\end{array}$} & \multirow{2}{*}{$\begin{array}{c}\text { Number of } \\
\text { operating CS }\end{array}$} & \multicolumn{2}{|c|}{$\begin{array}{c}\text { Fuel gas costs } \\
\left(\text { million } \mathrm{m}^{3} / \text { day }\right)\end{array}$} \\
\cline { 3 - 4 } & & $D=1400$ & $D=1000$ \\
\hline 1 & 2 & 0.257 & 0.143 \\
\hline 2 & 1,2 & 0.237 & 0.117 \\
\hline 3 & 1,3 & 0.256 & 0.161 \\
\hline 4 & 1 & 0.219 & 0.103 \\
\hline
\end{tabular}

The experimental results confirm the formation of a strategy of optimal treatment: maximum load early in the course of COP (see mode 4 in Table 1 ). Minimum number CS mode does not always guarantee its optimal (see. Modes 1 and 2 in Table 1 ).

5.2. Problem of operating mode scheduling. The numeric experiment in which calculated all possible operating modes of CS, held on the section Novopskov Pervomais'k with actual parameters of GCU and input data: ambient air temperature and ground temperature equal $10^{\circ} \mathrm{C}$; on the outlet of all CS's temperature equal $40^{\circ} \mathrm{C}$; outlet gas flow of CS Novopskov $Q=49.48$ million $\mathrm{m}^{3}$ /day; inlet pressure of CS Novopskov $=55.73$ at. We have to reach the pressure $P=57.05$ at on the outlet of CS Pervomaysk. The results of numerical experiment are given in Table 2.

Table 2. The simulation results of gas flow in the gas main.

\begin{tabular}{|c|c|c|c|c|}
\hline Number & CS Novopskov & CS Borova & CS Pervomais'k & Fuel costs \\
\hline 1 & & E: 1.29, Q: 47.79 & & \\
& P: $55.73: 55.73$ & P: $48.35: 62.17$ & P: $57.05: 57.05$ & \multirow{2}{*}{0.286} \\
& T: $17.56: 40.00$ & T: $19.31: 40.00$ & T: $19.75: 40.00$ & \\
\hline & & F: $0.29, \mathrm{~N}: 26.24$ & & \\
\hline & & P: $48.35: 48.35$ & P: 1.38, Q: 46.22 & \\
& & T: $: 55: 57.05$ & \multirow{2}{*}{0.297} \\
& T: $17.56: 45.40 .00$ & & F: $0.30, \mathrm{~N}: 29.61$ & \\
\hline 3 & E: 1.16, Q: 49.48 & & E: 1.07, Q: 46.22 & \\
& P: $55.73: 64.84$ & P: $58.73: 58.73$ & P: $53.25: 57.05$ & \multirow{2}{*}{0.408} \\
& T: $17.56: 32.00$ & T: $18.41: 40.00$ & T: $20.02: 27.40$ & \\
& F: $0.23, \mathrm{~N}: 20.37$ & & F: $0.18, \mathrm{~N}: 13.84$ & \\
\hline 4 & E: $1.14, \mathrm{Q}: 49.48$ & E: $1.09, \mathrm{Q}: 47.79$ & & \\
& P: $55.73: 63.27$ & P: $56.97: 62.17$ & P: $57.05: 57.05$ & \multirow{2}{*}{0.416} \\
& T: $17.56: 29.76$ & T: $18.53: 26.90$ & T: $19.74: 28.82$ & \\
& F: $0.22, \mathrm{~N}: 18.71$ & F: $0.20, \mathrm{~N}: 15.30$ & & \\
\hline
\end{tabular}

Table 2: E: 1.14, Q: 49.48, P: 55.73:63.27, T: 17.56:29.76, F: 0.22, N: 18.71 are gas flow compression ratio of gas flow through the CC, inlet and outlet CS gas pressure, CS inlet and outlet gas temperature, fuel gas costs, centrifugal supercharger drive capacity. 
It turned out that the operating point of CS Novopskov is located in the $10 \%$ surge zone and therefore CS Borova and CS Pervomaisk are used in operating mode (modes 1 and 2 in Table 2). The third mode was better than fourth because the CS Pervomais'k GCU's have better technical condition than the CS Borova. Considering the above, for the best performance of the gas main flows is proposed an algorithm.

Note that $i$ th CS operating mode, if it exists, is clearly defined by: parameters $\left(q_{i}, P_{1}^{i}, P_{2}^{i}, T_{1}^{i}\right)$ are inlet gas flow (mass flow or volumetric flow), inlet pressure and temperature and outlet gas pressure, capcity $W_{i}$. Each $i$ th CS has constrains such as the maximum capacity $W_{i \text { max }}$ and the maximum outlet pressure $P_{2}^{i} \max$. The given inlet pressure of 1 CS is $\bar{P}_{1}^{1}$ and outlet pressure of $n$th CS $\bar{P}_{2}^{n}$ $\left(P_{2 \max }^{n}>\bar{P}_{2}^{n}\right)$;

Main steps of the proposed algorithm.

1) The algorithm works in the direction of gas flow from the first to the $n$-th CS:

a) during thermohydraulic calculation we find the inlet pressure of $i$-th CS $P_{1}^{i}$;

b) if the CS can realizes one of the operating mode $\left(q_{i}, P_{1}^{i}, P_{2 \max }^{i}, T_{1}^{i}\right)$ or $\left(q_{i}, P_{1}^{i}, P_{2}^{i}, T_{1}^{i}\right)$ $\left(P_{2}^{i}<\bar{P}_{2}^{i} \max \right)$ on condition that it will operate with maximum capacity, then we consider that this CS is in the operating mode otherwise turn it off and continue analysis of $i+1$ th CS.

2) If the calculated pressure is lower than the given $\left(P_{2}^{n}<\bar{P}_{2}^{n}\right)$, then put the given pressure on the output of the last CS $\left(P_{2}^{n}=\bar{P}_{2}^{n}\right)$ and move in the opposite direction from $n$th

a) in the thermal-hydraulic calculation pressure we find the CS output pressure $P_{2}^{i}$ of $i+1$ th $(i<n)$ cascade in case the CS operating mode exists we complete the algorithm;

b) in case the CS operating mode does not exist $\left(q_{i}, P_{1}^{i}, P_{2}^{i}, T_{1}^{i}\right)$ we should find other $P_{1}^{i}$; It will be equal to one of two values: the minimum pressure $P_{1 \text { min }}^{i}$ from the domain $>P_{1}^{i}$ or the maximum pressure $P_{1 \text { max }}^{i}$ from the domain $<P_{1}^{i}$;

c) if it appears that it is changed the inlet pressure of the first $\operatorname{CS}\left(P_{1}^{1}\right)$ then the desired mode is impossible and the algorithm is completed.

3) If the calculated pressure $P_{2}^{n}$ satisfy the condition $P_{2}^{n}>\bar{P}_{2}^{n}$, then calculate the last cascade using the given pressure and do algorithmic analysis in the opposite direction:

a) perform thermal-hydraulic calculation and find the CS output pressures $P_{2}^{i}$ of $i+1 \operatorname{th}(i<$ $n$ ) cascade;

b) consider three possible cases: mode $\left(q_{i}, P_{1}^{i}, P_{2}^{i}, T_{1}^{i}\right)$ is implemented then algorithm is completed, otherwise find operating mode for the minimum pressure $P_{1 \text { min }}^{i}$ from the domain $>P_{1}^{i}$ or the maximum pressure $P_{1 \text { max }}^{i}$ from the domain $<P_{1}^{i}$. Not always there is the pressure in these domains for which there is the operating mode.

4) If after reverse moving the pressure in the first cascade is lower than the given $\left(P_{1}^{1}<\bar{P}_{1}^{1}\right)$ we consider operating modes with one operating CS $\left(\varepsilon^{i}>1, \varepsilon^{k}=1, k=1, \ldots, i-1, i+1, \ldots, n\right)$ after two $\left(\varepsilon^{i}>1, \varepsilon^{j}>1, \varepsilon^{k}=1, k=1, \ldots, i-1, i+1, \ldots, j-1, j+1, \ldots, n\right)$. In the case of a negative result the implementation of the given operating mode of the chain is impossible.

5.3. Problem of control of unsteady operating mode. In the general case a problem of control for GTS is formulated in such a way. For $[0, T]$ we need to find such a vector of control $\boldsymbol{u}\left(\left\{u_{i j}\left(t_{n}, t_{k} ; A_{i j}\right)\right\}, t\right) \in U$, for which $R_{s}(\boldsymbol{u}, s, t) \in R_{s}$, and which minimizes the optimality criterion $Q_{p}(0, T)=\int_{0}^{T} \sum_{i} q_{p i}\left(u_{i}, s_{i}, t\right) d t$, where $q_{p i}\left(u_{i}, s_{i}, t\right)$ is energy costs for operating mode of $i$ th CS at time $t$.

The main problem of control is minimization of $Q_{p}$ under keeping technological constraints and providing contract conditions and the given level of facility operating mode reliability and the system in general. A control is based on the following dependences

$$
q_{p} \leftrightarrow N_{e} \leftrightarrow\left(\text { scheme }-C S, P_{2 i-1}, n_{j}\right) \leftrightarrow N_{i_{j}} \leftrightarrow\left(P_{2 i-2}, P_{2 i-1}\right) .
$$


Technological constrains of the CS operation established by the inlet and outlet pressures and can be adjusted basing on the information about the change of accumulated gas volumes in the system. Too narrow given or calculated intervals of pressures require more frequent change of the CS operating modes which leads to an increase in wear of CS equipment. However, it can provide a more optimal operation of GM. In such cases, we have to find a compromise between optimality and durability of GCU operation. It is also useful to split the time interval of forecast into subintervals with similar boundary conditions and build optimal unsteady operating modes on each of them.

For automation of the transition process from the current operating mode to a predicted one we calculate constrains of CS controlled parameters such as pressure, flow rate and compression ratio. The rate of change of the CS operating modes is determined under the modelling unsteady modes. For such complicated systems, we have to follow the rule that at every time interval it is necessary to minimize the changes of facility operating modes. Since the unsteady modes in Ukraine's GTS are going slowly (for example, in the pipeline section they are going about three hours, and in the all GTS about several days). It is desirable first to carry out operating mode changes in the areas of the significant change of operating parameters. Most significant effects on the operating mode of the GTS are external inlet and outlet flow rate changes. Therefore, the CS's that are close to the places of gas flow perturbation must respond to such changes.

This approach makes it possible to automate the processes of CS turning on and off and maintain their controlled parameters within operating constrains. The values of constrains effect on the frequency of change of the CS operating modes, which is related with the intensity of equipment wear.

The simulation of the influence of control on operating parameters of the gas pipeline is shown in the following numerical experiment (the section of pipeline "Soyuz" CS Pysarivka - CS Bar, Fig. 2).

The boundary conditions on the inlet and outlet of the gas main and the control are given. We need to find an operating mode of all CS enabled in the operating mode under given outlet pressure constrains

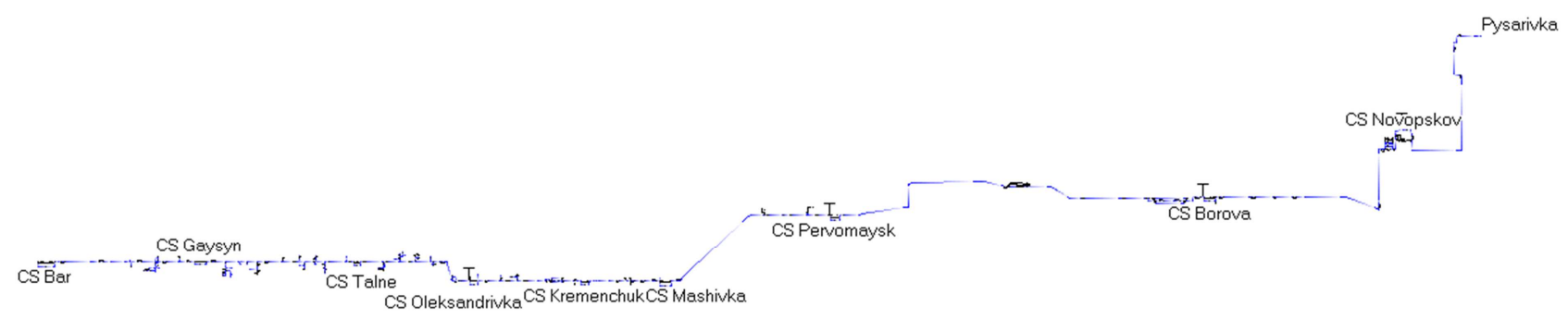

Fig. 2. Piping diagram.

The results of the simulation of gas-dynamic processes on the gas main under given initial-boundary conditions (Fig. 3).
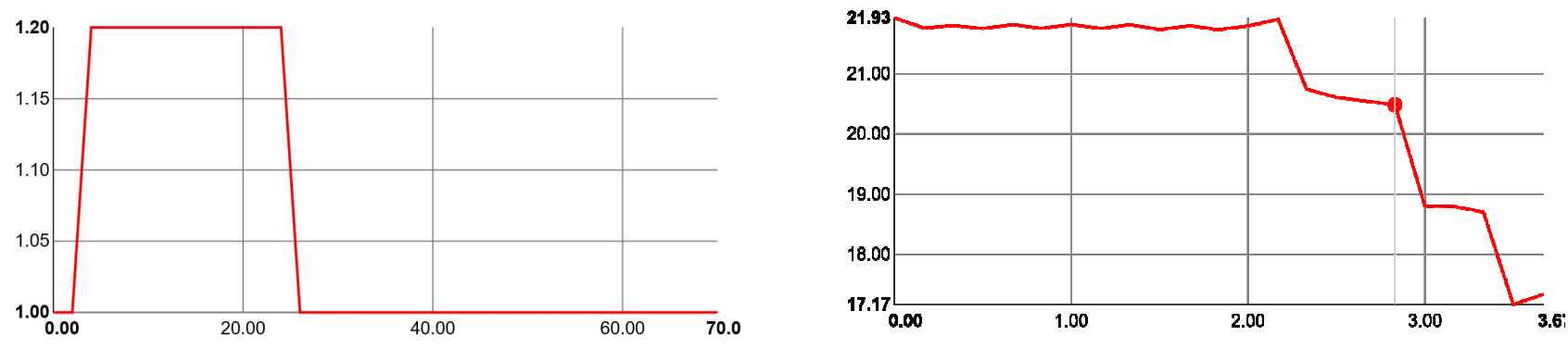

Fig. 3. Boundary conditions for the compression ratio (the dependence of compression ratio on time (hour)) at CS Borova (left). The boundary condition for CS Pervomaisk capacity (dependence of capacity (MW) on time (hour)) (right). 
CS Novopskov

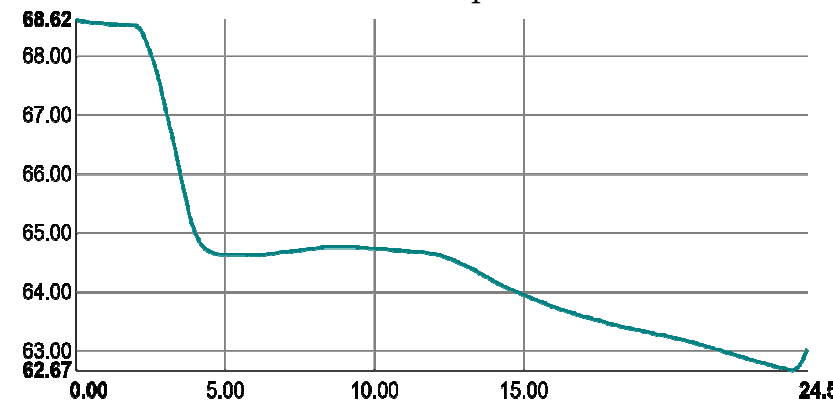

CS Pervomaisk

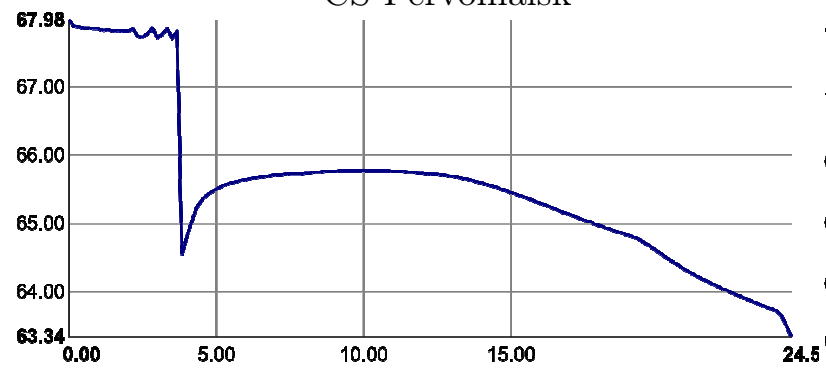

CS Kremenchuk

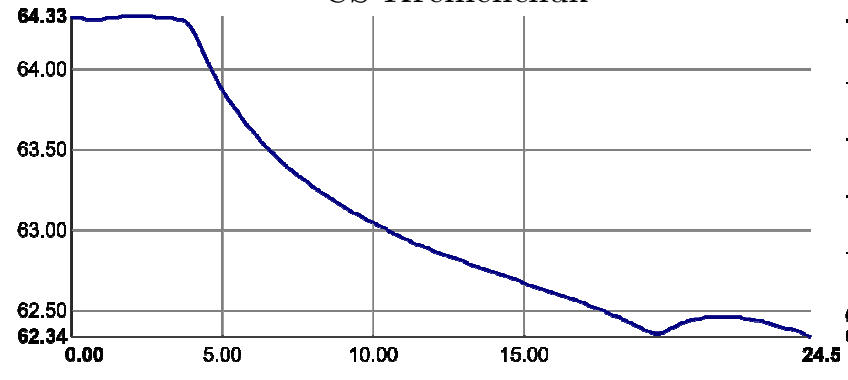

CS Talne

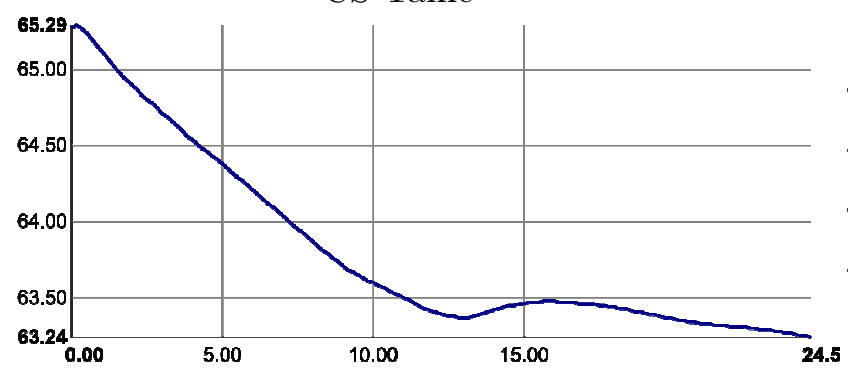

CS Borova

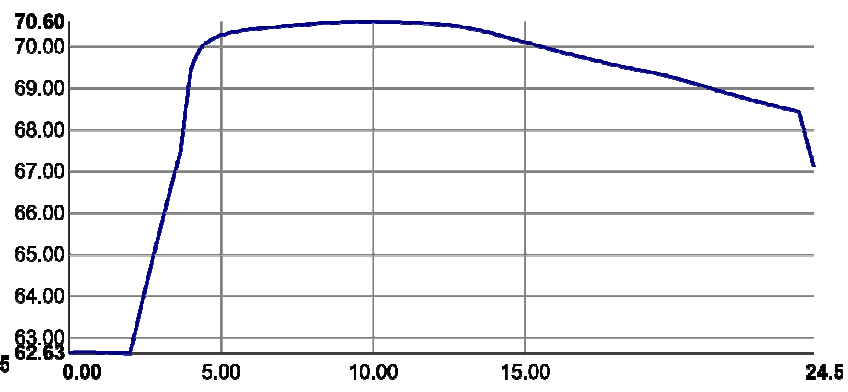

CS Mashivka

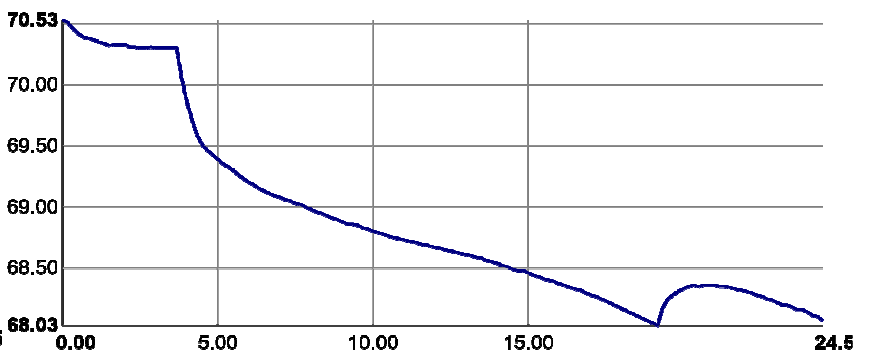

CS Oleksandrivka

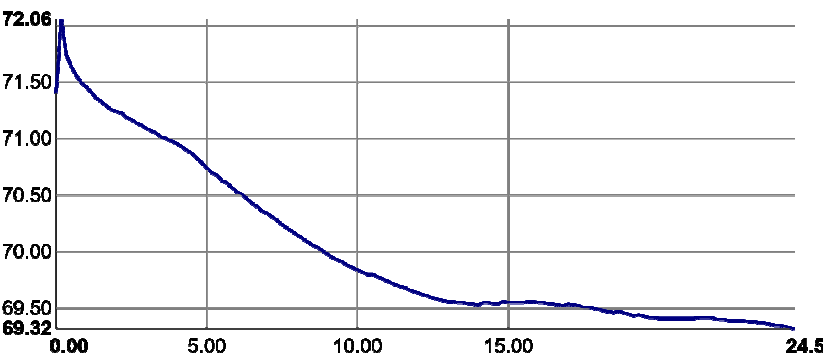

CS Gaisyn

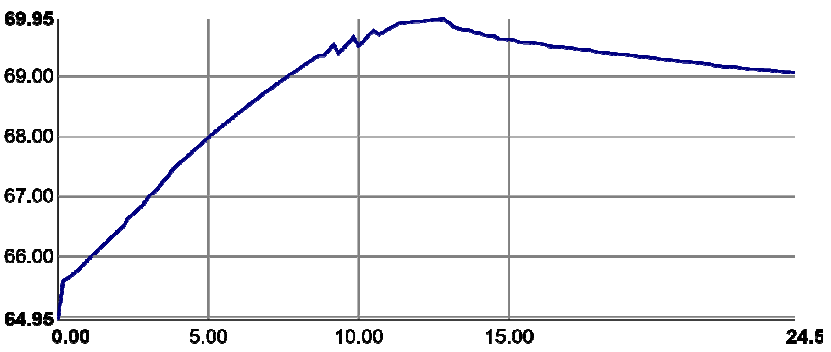

Fig. 4. The results of the modelling gas-dynamic processes. The dependence of CS outlet pressure (at) on time (hour).

\section{Conclusions}

It should be noted that if Ukraine's GTS is significant underloaded, we do not receive significant effects under gas cooling during the gas transmission. We can have the more significant effects of decreasing energy costs and increasing reliability of the gas transmission system under the effective facility operation. In this work we have proposed the approaches that provide automation of choosing optimal operating mode and finding control parameters of gas flows in the gas transmission system.

[1] Sardanashvily S. A. Raschotnyie metody i algoritmy. Moskva, Neft i gas (2005), (in Russian).

[2] Selesnev V. E., Aleshin V. V. and Klishin G. S. Metody i tehnologii chislennogo modelirovaniya gazoprovodnyh system. Moskva, Editorial URSS (2002), (in Russian). 
[3] Sinchuk Yu., Prytula N., Prytula M. Simulation of valve operation on gas main. The Bulletin of Lviv Polytechnic National University titled "Computer sciences and information technologies". 663, 216-223 (2010), (in Ukrainian).

[4] Sinchuk Yu., Prytula N., Prytula M. Simulation of unsteady operating mode of gas networks. The Bulletin of Lviv Polytechnic National University titled "Computer sciences and information technologies". $66 \mathbf{6 3}$ 128-132 (2010), (in Ukrainian).

[5] Pyanylo Ya., Prytula M., Prytula N. and Lopuh N. Models of mass transfer in gas transmission systems. Mathematical modeling and computing. 1, n. 1, 84-96 (2014).

[6] Boyaryn I., Borovyy R., Gryniv O. and others. Optimization of the multishop compressor stations operation with multitype gas compressor units. The Bulletin of Lviv Polytechnic National University titled "Computer sciences and information technologies". 672, 326-335 (2010), (in Ukrainian).

[7] Prytula N., Prytula M., Dacuk A. and others. Optimization of the operating modes of gas transmission system. The Bulletin of Lviv Polytechnic National University titled "Computer sciences and information technologies". 694, 395-401 (2011), (in Ukrainian).

[8] Prytula N. Problems of optimization of gas flow distribution in gas transmission system. The Bulletin of Lviv Polytechnic National University titled "Computer sciences and information technologies". 604, 220-227 (2007), (in Ukrainian).

[9] Prytula N. Calculation of the flow distribution in the gas transmission system (steady case). Physical and mathematical modeling and information technologies. 5, 146-157 (2007), (in Ukrainian).

[10] Prytula N. Problems of flow control in gas transmission system. The Bulletin of Lviv Polytechnic National University titled "Computer sciences and information technologies". 732, 375-382 (2012), (in Ukrainian).

[11] Bellman R. Dynamichiskoe programirovaniye. Moskva (1960), (in Russian).

[12] Pontryagin L. S., Boltyanskii V. G., Gamkrelidze R. V. and others. Matematicheskaya teorija optimalnyh processov. Moskva, Nauka (1976), (in Russian).

[13] Srochko V.A. Iteracionnyje metody resheniya zadach optimalnogo upravleniya. Moskva, Phizmatlit (2000), (in Russian).

[14] Hartl R. F., Sethi S. P., Vickson R. G. A Survey of the Maximum Principle for Optimal Control Problems with State Constraints. SIAM Review. 37, n. 2, 181-218 (1995).

\title{
Оптимізація неусталених режимів роботи магістральних газопроводів
}

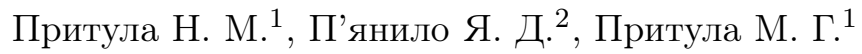 \\ ${ }^{1}$ Філія "Науково-дослідний інститут транспорту газу" ПАТ "УКРТРАНСГАЗ" \\ вул. Маршала Конева, 16, 61004, Харків, Україна \\ ${ }^{2}$ Центр математичного моделювання Інституту прикладних проблем механіки $і$ математики \\ ім. Я. С. Підстригача НАН Украӥни \\ вул. Д. Дудаєва, 15, 79005, Львів, Україна
}

Розглянуто задачу керування режимами роботи компресорних станцій для забезпечення оптимального режиму роботи магістрального газопроводу в широких діапазонах зміни об'ємів транспортування газу за різних можливих варіантів початкових та крайових умов. Запропоновано адаптивний алгоритм формування керуючих дій, який забезпечує критерій оптимальності і водночас не порушуються наявні технологічні обмеження.

Ключові слова: магістральний газопровід, оптимальний режим, критерій оптимальності, компресорна станція, керування.

2000 MSC: $76 \mathrm{~N} 25,49 \mathrm{~J} 20$

УдК: 621.64 .029

Mathematical Modeling and Computing, Vol.3, No. 2, pp. 183-190 (2016) 